\title{
Eğitim Kurumları için Bilgi Yönetim Sisteminin Tasarımı ve Geliştirilmesi
}

\author{
M. Hanefi Calp ${ }^{1 *}$, Resul Bütüner ${ }^{2}$, Yusuf Uzun ${ }^{3}$ \\ ${ }^{1}$ Karadeniz Teknik Üniversitesi, İktisadi ve İdari Bilimler Fakültesi, Yönetim Bilişim Sistemleri Bölümü, Trabzon, Türkiye, (ORCID ID 0000-0001-7991-438X), \\ mhcalp@ktu.edu.tr \\ ${ }^{2}$ Bilişisim Teknolojileri Öğretmeni, Ankara Beypazarı Fatih MTAL, Ankara, Türkiye (ORCID ID 0000-0002-9778-2349), rbuutner@gmail.com \\ ${ }^{3}$ Necmettin Erbakan Üniversitesi, Mühendislik Fakültesi, Bilgisayar Mühendisliği Bölümü, , Konya, Türkiye, (ORCID ID 0000-0002-7061-8784), \\ yuzun@erbakan.edu.tr
}

(DOI: 10.31590/ejosat.1015188)

ATIF/REFERENCE: Calp, M.H., Bütüner, R., Uzun, Y. (2021). Eğitim Kurumları için Bilgi Yönetim Sisteminin Tasarımı ve Geliştirilmesi. Avrupa Bilim ve Teknoloji Dergisi, (28), 1304-1308.

$\ddot{O} z$

Teknolojik gelişmelerle birlikte hemen hemen her alanda önemli ölçüde veri artışı gözlemlenmektedir. Veri hacmindeki artış büyük veri kavramını gündeme getirmiştir. Kurumlar için artan bu büyük verinin etkin ve verimli bir şekilde kullanılması ancak bilgi yönetim süreçlerinin uygulanmasıyla mümkündür. Bilgi yönetimi sayesinde, eğitimin tüm paydaşları bilgiye daha kolay ulaşabilecek, tüm faaliyetlerini zamandan ve mekandan bağımsız bir şekilde gerçekleştirebilecek ve daha kısa sürede etkin kararlar alabileceklerdir. $\mathrm{Bu}$ bağlamda, bu motivasyonla çalışmada eğitim-öğretim kurumları için bir bilgi yönetim sistemi tasarlanmış ve geliştirilmiştir. Çalışmada, uygulamanın arayüzünün geliştirilmesi ve yayınlanması için PHP, JAVA, HTML programlarından, bilginin depolanması ve gerektiğinde sorgulama yapılabilmesi için de MYSQL veritabanı programından yararlanılmıştır. Geliştirilen sistem ile yöneticiler, öğretmenler ve öğrenciler tüm süreçte kendileri ile ilgili bilgiye (kurum bilgileri, not girişi, ders programları, devamsızlık bilgileri, toplantılar, duyurular vb.) kolaylıkla erişim sağlayabilmekte ve zamanlarını etkin bir şekilde kullanabilmektedir. Sonuç olarak, çalışma bilgi yönetim sistemlerinin tüm adımlarını içermekte ve konuyla ilgili farkındalık oluşturulması adına önem arzetmektedir.

Anahtar Kelimeler: Eğitim Kurumları, Bilgi, Bilgi Yönetimi, Sistem, Tasarım

\section{Design and Development of the Knowledge Management System for Educational Institutions}

\begin{abstract}
A significant increase in data is observed in almost every field with the technological developments. The increase in data volume has brought the concept of big data to the agenda. Effective and efficient use of this increasing big data for institutions is only possible with the application of knowledge management processes. Thanks to knowledge management, all stakeholders of education will be able to access information more easily, perform all their activities independently of time and place, and take effective decisions in a shorter time. In this context, in this study, an knowledge management system was designed and developed for educational institutions with this motivation. In the study, PHP, JAVA, HTML programs were used for the development and publication of the application's interface, and MYSQL database program was used for storing information and querying when necessary. With the developed system, administrators, teachers and students can easily access information about themselves (institutional information, grade entry, course schedules, absenteeism information, meetings, announcements, etc.) and use their time effectively throughout the process. As a result, the study includes all steps of knowledge management systems and is important for raising awareness on the subject.
\end{abstract}

Keywords: Educational Institutions, Knowledge, Knowledge Management, System, Design 


\section{Giriş}

Günümüzde eğitim-öğretim kurumlarının sahip olduğu sistemler genel anlamda hızlı bir şekilde gelişmekte ve her geçen gün daha da karmaşık bir hal almaktadır. Bu durum hem karar vericiler hem de eğitimin her kademesindeki yöneticiler için büyük zorlukları beraberinde getirmektedir. $\mathrm{Bu}$ zorlukları ortadan kaldırabilmek ve eğitim sistemlerinin hedeflerine ulaşabilmek için eğitim sürecindeki karar vericilerin farklı kaynaklardan elde edecekleri anlık ve güncel farklı türde verilere ihtiyaçları vardır [1], [2], [3]. Yani, sürekli değişen ve gelişen bilgi ihtiyacına cevap verebilmek için otoriteler karar verme süreçlerini desteklemeli, kurum için gerekli veri kaynağı toplanmalı ve toplanan veriler dikkatle analiz edilmelidir [4].

Dolayısıyla bu çerçevede, eğitim-öğretim süreçlerinin kalitesinin sürekli izlenmesi, kurumsal bilgi alt yapısının oluşturulması, analiz edilmesi, sunumu ve uygulanmasıyla ilgili adımları içeren bilgi yönetim sistemleri gündeme gelmektedir. $\mathrm{Bu}$ da ancak bilgi ve iletişim teknolojilerinden yararlanılması ve etkin bir şekilde kullanılmasıyla mümkündür [5]. Bu bağlamda, bilgi ve iletişim teknolojileri, verilerin kaydedilmesi, depolanması, belirli bir işlem sürecinden geçirerek yeni bilgilerin üretilmesi, üretilen bu bilgilere ihtiyaç halinde erişilmesi ve paylaşılması gibi süreçlerin etkili ve verimli bir şekilde gerçekleştirilmesine imkan sağlar [6].

Bilgi teknolojisindeki gelişmeler kurum veya organizasyonlara önemli katkılar sağlamaktadır. Bu katkılar dikkatli bir şekilde değerlendirilmeli ve sözkonusu teknolojiler çağın imkan ve ihtiyaçlarına göre güncellenmelidir. Çünkü bu teknolojiler stratejik amaç ve öneme sahiptir. Bilgi teknolojilerinin örgütlere sundukları stratejik avantajları değerlendirebilmek için herşeyden önce bilgi sistemlerinin organizasyonlardaki rollerini tespit etmek, anlamak ve çözümlemek gerekir. Bilgi sistemleri, örgütlerde uygulanan karar alma fonksiyonunu desteklemek amacıyla vardır. Bilginin amacı, muhtemel bir süreç, olay veya durumla ilgili oluşabilecek belirsizliği en azından minimuma indirmektir. Ancak, bilgi sistemleri, karar alma süreçlerinde ihtiyaç duyulan ve kullanılan bilgileri sağlamayı hedeflemektedir. Bilgi sistemleri, hangi verilerin toplanacağını ve nasıl işlenerek analiz edileceğini tespit eden kurallar bütünüdür. Bir başka ifadeyle, bilgi sistemleri belirli hedeflere ulaşabilmek amacıyla karar vericiler için verileri anlamlı bilgilere çeviren insan gücü, program ve yönetsel süreçlerdir [7].

Örgütlerde bilgi ve iletişim teknolojilerine dayalı bir bilgi sistemi tasarlamak ve geliştirmek için bilgiye olan ihtiyaç iki düzeyde belirlenmelidir. Bunlar örgüt ve uygulamadır. Örgütün bilgi mimarisi, örgüt düzeyinde belirlenecek bilgi ihtiyacı ile tanımlanmış olur. Uygulama düzeyindeki bilgi ihtiyacı dikkate alınarak geliştirilecek bir bilgi sistemi ise, örgütün bir birimine ya da bir faaliyetine hizmet sunar [8].

Teknolojideki gelişim, eğitim-öğretim süreçleri üzerinde de oldukça etkili olmuş ve teknolojik araçların eğitime entegre edilmesi gibi birtakım değişiklikler meydana gelmiştir. Ancak teknolojinin temin edilmesiyle birlikte etkin bir şekilde kullanılması da önemlidir, çünkü bu durum eğitim süreçlerinin daha hızlı ilerlemesine yol açacaktır. Örgütler bilgiye ulaşılması, temin edilmesi, bilginin analiz edilmesi ve üretilmesi için internet teknolojisinden yararlanılarak elde ettikleri verileri elektronik ortama taşıyabilir ve böylece erişilebilirliği de sağlayabilirler. $\mathrm{Bu}$ amaçla geliştirilen mobil veya web tabanlı sistemler; mekândan bağımsız bir şekilde erişilebilirlik, çevrimiçi işlem yapabilme, zamandan tasarruf sağlama gibi birçok önemli kolaylık sağlamaktadır [9]. Bilginin karar verme süreçleri üzerindeki öneminin anlaşılmasıyla birlikte, doğru bilgiye, doğru zamanda ve doğru kanallardan erişebilmek istenmektedir. $\mathrm{Bu}$ bağlamda, teknolojik yeniliklerin yayılımı eğitim-öğretim kurumları içerisinde de gerçekleşmekte ve sözkonusu kurumlar bilgi yönetim sistemlerine yönelmektedirler [10], [11].

Bu çalışmanın amacı, eğitim-öğretim kurumları için bir bilgi yönetim sistemi tasarlamak ve geliştirmektir. Geliştirilen sistem ile yöneticiler, öğretmenler ve ögrenciler tüm süreçte kendileri ile ilgili bilgiye (kurum bilgileri, not girişi, ders programları, devamsızlık bilgileri, toplantılar, duyurular vb.) kolaylıkla erişim sağlayabilecek ve zamanlarını etkin bir şekilde kullanabileceklerdir. Bu bağlamda çalışmanın ikinci bölümünde, bilgi yönetim sistemleri hakkında genel bilgi verilmiştir. Üçüncü bölümde, kullanılan yöntem ve tekniklere; son olarak dördüncü bölümde ise çalışamadan çıkarılacak sonuç ve önerilere yer verilmiştir.

\section{Bilgi Yönetim Sistemleri}

Bilgi yönetim sistemleri, örgütlerin faaliyetlerini optimize etmek amaciyla zamandan ve bütçeden tasarruf etmek için bilginin yönetilmesi olarak tanımlanır [10], [11]. Bilgi yönetim sistemleri sayesinde, toplanan veriler, gerekli birimlere eksiksiz ve zamanında iletilmektedir. Böylece bilgiye ulaşmak ve bilgi paylaşımı yapmak için harcanan zaman kısalmakta, kurumların etkinliği artmaktadır. Bilgi yönetim sistemi, karar vericilerin ihtiyaçlarını gidermek amacıyla, üst yönetimden alt düzeye doğru, kullanılan sistemin de hedeflerini dikkate alarak geliştirilir. Bilgi yönetim sistemi, bilgisayar temeline dayanan insan-makine sistemi olup bilgi ve karar desteği sağlayan bir araçtır [12], [13]. Bilgi yönetimi süreçleri bilginin elde edilmesi (üretilmesi), seçilmesi, organize edilmesi, depolanmasi, paylaşılması ve kullanılması (uygulanması) olarak ifade edilmektedir [14], [15].

Literatürde bilgi yönetim sistemlerine farklı bakış açıları vardır. Ancak, neredeyse tüm araştırmacılar bilgi yönetim sistemlerinin işletmeye veya üretim yapılan kuruma çok büyük katkıları olduğunu düşünmektedirler. $\mathrm{Bu}$ noktada Vukašinović ve diğerleri, bilgi yönetim sisteminin faydalarını aşağıdaki gibi listelemektedirler [16]:

- Bilgi ve kaynakların iyileştirilebilirliği,

- Hatalar sonucunda öğrenmenin sağlanması ve sürecin sürekli iyileştirilmesi,

- İyi uygulamalara yönlendirmesi,

- İşletme içinde daha hızlı ve gelişmiş karar alınabilmesi,

- Personellerin iyileştirilmiş ortamı ve özverisi,

- Tecrübeli personel kaybının azaltılması,

- Bilgi kopyalamaya karşı koruma sağlanması,

- Bir ürünün geliştirilmesi ve piyasaya sunulması için daha az zaman harcanmas1,

- Geliştirilmiş marka bilinirliği,

- Piyasadaki olası değişikliklerin daha erken tespiti

Bu tanımlar 1şığında, literatürde yaygın olarak kullanılan her bir adım kısaca şu şekilde açıklanabilir: 
Bilginin elde edilmesi (üretilmesi): Kurum içi veya dış1 muhtelif yollarla, örgütün kendi iş süreçlerinden veya faaliyetlerden veya paydaşlarla iletişimi olan diş kaynaklardan elde edilir [17].

Bilginin depolanmast: Toplanan verilerin bilgi tabanıyla ilişkilendirilmesi ve böylece bilginin kullanımı açısından sürekliliğinin sağlanması anlamına gelmektedir. Gerektiği zaman bilgiye kolay ve hızlı bir şekilde erişim sağlanabilmesi için bilginin kaybolmadan etkin bir şekilde depolanması gerekir. Depolama yalnızca fiziksel anlamda değil, aynı zamanda personellerin hafizası veya örgütsel hafiza olarak da düşünülebilir [18], [19], [20].
Bilginin paylaşılması: Organizasyonlarda bilgi kaynağının tüm paydaşlarla paylaşılmasıdır. Doğru zamanda doğru bilgiyi paylaşmak sürecin önemli adımlarından biridir [21].

Bilginin kullanılması (uygulanması): Örgütün planlanan hedeflere ulaşmak amacıyla hızı bir şekilde uygulanması veya kullanılmasıdır. Bu adımda, bilgi etkin bir şekilde kullanılmakta, sonuçlar değerlendirilmekte ve ihtiyaç halinde süreç yeniden şekillenmektedir. Bununla birlikte, bilginin kullanılması veya uygulanması örgüt için bilginin daha uygun bir hal alması anlamına gelir [17].

Ayrıca, bilgi yönetim sistemlerini geliştirmeden önce yönetim stratejisini belirlemek gerekmektedir. Şekil 1'de, bilgi yönetim stratejisi geliştirme ve uygulama modeline yer verilmiştir.

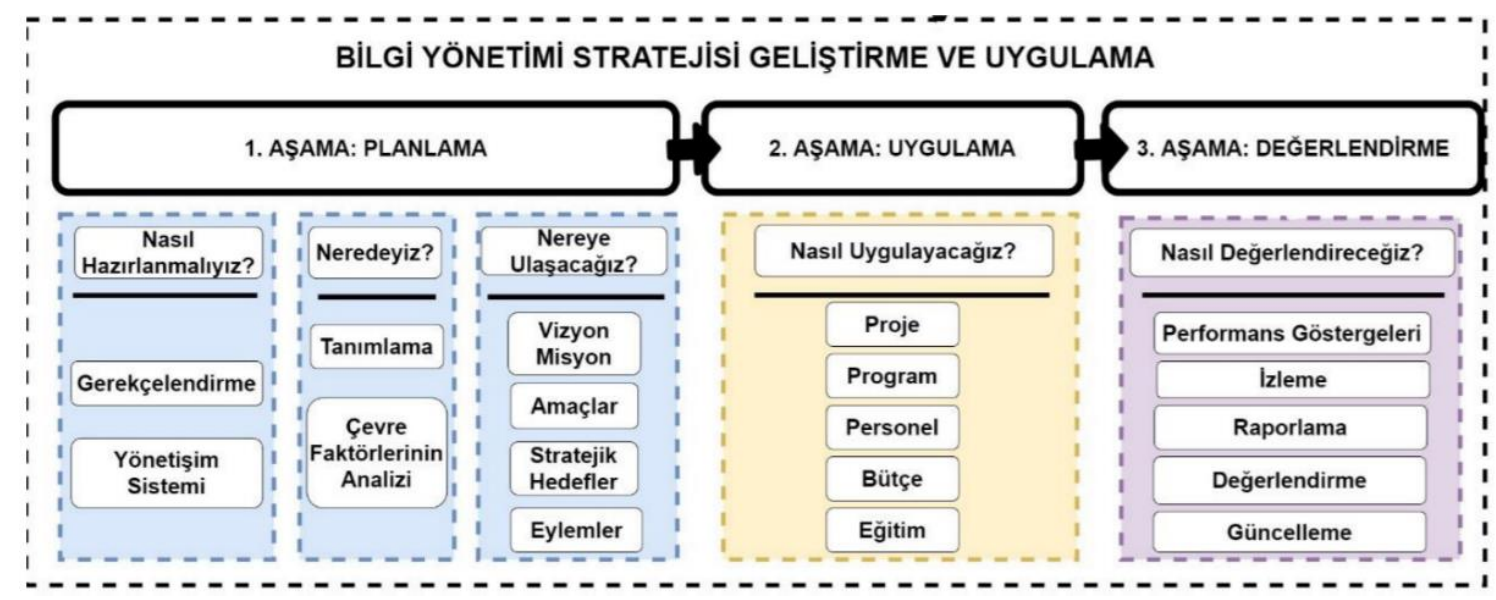

Şekil 1. Bilgi yönetim stratejisi geliştirme ve uygulama modeli [22]

Bilgi yönetim sistemlerini eğitim alanında irdelemek ve tanımlamak gerekirse, bir bilgi yönetim sistemi yöneticilerin, öğretmenlerin, öğrencilerin ve velilerin bulunduğu bir sosyal sistemdir. Bunun en iyi örneklerinden biri öğrenciler, öğretmenler, yöneticiler ve veliler için geliştirilen Okul Bilgi Yönetim Sistemleridir. Okul bilgi yönetim sistemleri kaliteli eğitim hizmeti yönünde önemli bir faktördür [23], [24]. Okul bilgi sistemlerindeki başarı durumu, sahip olduğu karmaşık yapının ve onu oluşturan kısımların etkili bir şekilde entegre edilmesine bağlıdır [25].

Eğitimde kullanılan bilgi yönetim sistemleri, planlama, kaynakların paylaşımı, izleme ve değerlendirme, strateji geliştirme ve karar verme adımlarını gerçekleştirmek için verilerin toplanması ve analiz edilmesi amacıyla geliştirilen sistemlerdir [26]. Eğitimde kullanılan bilgi sistemleri her kademedeki eğitim-öğretim faaliyetlerinin yönetimini desteklemek için doğru zamanda ve düşük maliyetle bilgi sağlamak amacıyla kullanıcıları, teknolojiyi ve süreçleri bir araya getiren sistemlerdir. Eğitim bilgi sistemlerinin etkin bir şekilde icra edilmesinde "faydalılık", "kullanım kolaylı̆̆ı" ve "iş/görev ile uyumluluk" olmak üzere üç temel kavram ön plana çıkmaktadır [27], [28]. Sözkonusu sistemler bir başka tanıma göre ise; eğitim-öğretim süreçlerinde verilmesi muhtemel kararlarda kullanılmak için eldeki verilerin düzenli olarak paylaşıldığ süreçler, prosedürler ve işbirliği olarak ifade edilmektedir. Verilen kararların bilgiye dayalı olması daha etkili izleme ve değerlendirme, planlama, strateji geliştirme ve analiz etme kolaylığ sağlamakta ve eğitimde verimliliği ve kaliteyi artırmaktadır [29]. Bununla birlikte, bilgi sistemleri eğitim sisteminin yönetim, strateji, planlama ve izleme-değerlendirme faaliyetlerini içermektedir. Eğitim yönetimi sürecinde bilgi sistemleri paydaşları, mevcut durum, verimlilik, kurumsal faaliyetler, performans, problemler ve ihtiyaçlar gibi konularda bilgi verici olmalıdır [30].

\section{Yöntem ve Teknik}

$\mathrm{Bu}$ çalışmada eğitim-öğretim kurumları için bir bilgi yönetim sistemi tasarlanmış ve geliştirilmiştir. Bilgi yönetiminin tüm adımları dikkate alınarak sürecin işletilebilmesi için PHP, JAVA, HTML programları ve bilginin depolanması ve gerektiğinde sorgulama yapılabilmesi adına MYSQL veritabanı programından yararlanılmıştır. Geliştirilen sistem ile yöneticiler, öğretmenler ve öğrenciler tüm süreçte kendileri ile ilgili bilgiye (kurum bilgileri, not girişi, ders programları, devamsızlık bilgileri, toplantılar, duyurular vb.) kolaylıkla erişim sağlayabilmekte ve zamanlarını etkin bir şekilde kullanabilmektedir.

Uygulamada Öğrenci, Öğretmen ve Akademik Bilgi ana modülleri bulunmaktadır (Şekil 2). 


\section{European Journal of Science and Technology}

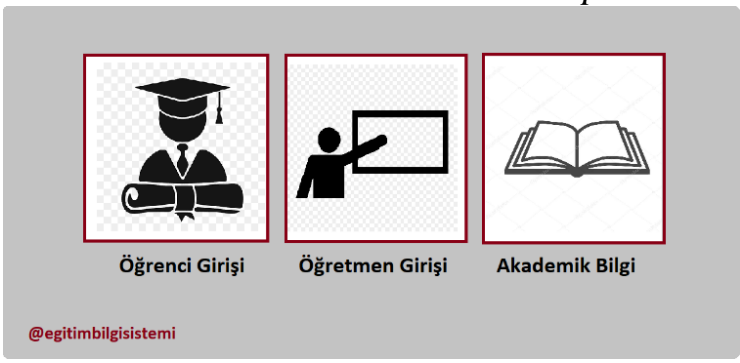

Şekil 2. Uygulamada bulunan ana modüller

Sisteme giriş yapmak isteyen öğretmenler, T.C. numaraları ile öğrenciler ise okul numaraları ile giriş yapmaktadırlar. Tüm kullanıcılar, istedikleri bilgilere hızlı ve kolaylıkla ulaşım sağlayabilmekte ve istedikleri güncellemeleri yapabilmektedirler. Böylece, bilgi yönetiminin de ilk aşaması olan bilginin elde edilmesi veya toplanması aşaması gerçekleşmiş olmaktadır.

Bununla birlikte, muhtelif yollarla elde edilen bilginin kayıt altına alınması amacıyla veritabanı tasarlanmış ve ilgili tablolar oluşturulmuştur. Sözkonusu tablolar; belgeler, duyurular, öğretmenler, dersler, sınıflar, ders programı, dönem, sınav tarihleri, öğrenci bilgileri, devamsızlık bilgileri, not bilgileri olarak belirlenmiştir. Şekil 3'te oluşturulan veritabanındaki tablolar ve bu tablolar arasındaki ilişkilere yer verilmiştir.

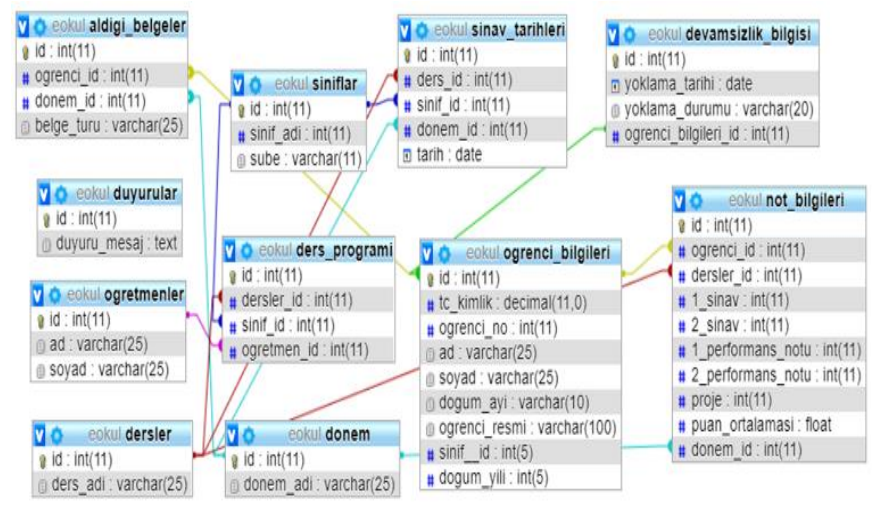

Şekil 3. Veritabanı tabloları ve ilişkiler

Yapılan girişler neticesinde sistemin veritabanında veriler kaydedilmektedir. Bu aşama, bilgi yönetiminin bir aşaması olan bilgilerin depolanma/kaydedilme aşamasıdır. "Öğrenci” girişi ile sisteme giriş yapılarak ders, ders kodu, ders programı, kredi, ders notu vb. bilgilere ulaşllabilmektedir. "Öğretmen” girişi ile sisteme giriş yapılarak kişisel bilgiler, not bilgileri, ders programı vb. bilgilere ulaşılabilmektedir. Ayrıca, kullanıcılar "Akademik Bilgi" aracılığıyla ile yıl içerisinde ihtiyaç duydukları tüm akademik bilgilere (dönem sınav takvimi, kayıt bilgileri, öğrenci işleri vb.) kolaylıkla erişim sağlayabilmektedirler.

Daha sonra, muhtelif yollarla temin edilen ve sisteme kaydedilen bilgiler tüm paydaşlarla paylaşılabilmekte (bilginin paylaşılması) ve gerekli görüldüğü takdirde etkin bir şekilde kullanılabilmektedir (bilginin kullanılması veya uygulanması).

\section{Sonuç ve Öneriler}

Bu çalışmada, öğretmen, öğrenci ve akademik bilgi modülleri geliştirilerek eğitime katkı sunacak yenilikçi yaklaşımla bir bilgi yönetim sistemi geliştirilmiş ve sonuçları aktarılmıştır. Geliştirilen bilgi yönetim sistemi kullanılarak bilginin elde edilmesi, işlenmesi, depolanması ve ihtiyaç halinde paydaşlara iletilmesi veya herhangi bir yerden bu bilgiye erişim sağlanması otomatik olarak gerçekleştirilebilmektedir. Çalışma öğrenci, öğretmen, yönetici ve velilerin eğitime ait tüm bilgilere kısa zamanda ve etkili bir şekilde erişmesine imkan vermektedir. Böylece tüm kullanıcıların daha etkin karar vermeleri sağlanmaktadır.

Ayrıca, eğitim-öğretim kurumlarının iş süreçlerinde yenilikçi yaklaşımların etkin olarak kullanılması örgüt kültürünü oluşturmakta ve bilgi yönetim süreçlerinin etkin bir şekilde uygulanmasında önemli rol oynamaktadır. Bu durum, eğitim kurumlarının daha esnek ve yapılandırılmış bir bilgi yönetim kültürüne sahip olmalarını sağlamaktadır.

Eğitim-öğretim süreçlerinde etkin ve başarılı bir yönetim anlayışının sağlanabilmesi için uygulanabilir stratejilerin geliştirilmesi ve sürecin bilgi tabanıyla sürekli izlenmesi gerekmektedir. Dolayısıyla, eğitimsel verilerin toplanması, işlenmesi, entegre edilmesi ve analiz edilerek raporlanması önem arz etmektedir. Bununla birlikte, birçok eğitim-öğretim kurumunda bilgi yönetim sistemleri olmasına rağmen sözkonusu sistemlerin kullanılması ve sonuçlarının analiz edilmesi bakımından çok fazla ilgi görmemektedir.

Son olarak geliştirilen uygulama, kullanılabilirlik açısından da oldukça iyi düzeyde olup e-okul kapsamında ihtiyaç duyulan birçok hizmet bulunmaktadır. Bununla birlikte, kullanıcıların eğitim-öğretim süreçlerindeki bilgi yönetim sistemlerine ait memnuniyet durumları ve memnuniyeti etkileyen tüm faktörler eksiksiz bir şekilde belirlenmelidir. Bu noktada, ileride yapılacak çalışmalarda yazılımdan kaynaklanan hatalar minimize edilebilir ve sistem karmaşıklığı sadeleştirilebilir. Yani daha kullanıcı dostu veya kullanılabilir bir sistem geliştirilebilir. Çünkü, kullanılabilir sistemler kullanıcılar tarafından belirli amaçlarda etkili, verimli, hata payı az ve kaliteli bir hizmet sunma imkânı sağlamaktadır. Sonuç olarak, gerçekleştirilen çalışmanın bir farkındalık oluşturması bakımından önemli olduğu düşünülmektedir.

\section{Kaynakça}

[1] Samancioğlu, M., Bağlıbel, M., Özmantar, Z. K., \& Çetin, H. (2015). Okul Yöneticilerinin Eğitim Yönetimi Bilgi Sistemlerine İlişkin Görüşleri: Memnuniyet, Algılanan Fayda Ve Göreve Uygunluk Arasındaki İlişki. Balıkesir Üniversitesi Sosyal Bilimler Enstitüsü Dergisi, 18(34), 193-212.

[2] Cassidy, T. (2005). Education Management Information System (EMIS) Development in Latin America and the Caribbean: Lessons and Challenges. Retrieved from http://41.89.160.5/chisimba/usrfiles/context/lpe803/ EMIS_-_What_is_it_4.pdf.

[3] Sultana, R. G. (2002). An EMIS for Palestine - The Education Management Information System in The West Bank And Gaza Strip. Mediterranean Journal of Educational Studies.

[4] Wako, T. N. (2003). Education Management Information Systems (EMIS): An overview Available from http://www.educationcaribbean.com/eDocs/ ICT4E/EMIS.pdf. 
[5] Billeh, V. (2001). Educational management and information systems and decision making. In V. Billeh \& E. Abd-El Mawgood (Eds.), Education Development Through Utilization of Technology. Beirut: Unesco Regional Office \& United Arab Emirates: Ministry of Education and Youth.

[6] Behan, K., \& Holmes, D. (1990). Understanding information technology: text, readings, and cases. Prentice Hall.

[7] Lucas, H. C. (1973). Computer-based information systems in organizations. Chicago: Science Research Associates.

[8] Lederer, A. L., \& Mendelow, A. L. (1988). Information systems planning: top management takes control. Business Horizons, 31(3), 73-78.

[9] Mutlu Bayraktar, D. (2017). E-Okul Yönetim Bilgi Sisteminin Kullanılabilirliğinin Göz İzleme Yöntemi İle Değerlendirilmesi. Itobiad: Journal of the Human \& Social Science Researches, 6(5).

[10]Işın, B., (2000), "Bankacılık Sektörü ve Teknoloji Araçlarının Bankacılık Sektörüne Uygulanması-1”, Banka ve Para Teknolojileri Dergisi, Mart, Nisan, Y1l:2, Sayı:7, s 60.

[11]Saldamlı, A. (2008). İnsan kaynakları yönetiminde bilişim teknolojisinin kullanımına yönelik bir araştırma: Tekirdağ örneği.

[12]Miman, M., Yoğun, A. E., \& Önel, Y. E. Yönetim Bilgi Sistemleri Kullanım Özellikleri Arasındaki İlişkiler: Lojistik Sektörü Üzerine Bir Çalışma. Akademik Bakış Uluslararası Hakemli Sosyal Bilimler Dergisi, (54), 161173.

[13]Laudon, K. C., \& Laudon, J. P. (1996). Management information systems: organization and technology. Prentice-Hall, Inc.

[14]Calp, M. H. (2020). Knowledge Management Within the Context of Organizational Innovation. In Advanced MIS and Digital Transformation for Increased Creativity and Innovation in Business (pp. 26-49). IGI Global.

[15]Çetinkaya, A. (2012). Örgütsel Bilgi Yönetim Sürecinde Bilgi Yönetim Performansı Boyutları: Ölçek Geliştirme Ve Geçerliliği Üzerine Bir Araştırma.

[16]Vukašinović, N., Vasić, D., \& Tavčar, J. (2018). Application of Knowledge Management System to Injection Mold Design and Manufacturing in Small Enterprises. In DS92: Proceedings of the DESIGN 2018 15th International Design Conference (pp. 1733-1744).
[17]Selvi, Ö. G. Ö. (2012). Bilgi toplumu, bilgi yönetimi ve halkla ilişkiler. Gümüşhane Üniversitesi İletişim Fakültesi Elektronik Dergisi, 1(3).

[18]Kalkan, V. D. (2006). Örgütsel öğrenme ve bilgi yönetimi. Elektornik Sosyal Bilimler Dergisi, 5(16), 22-36.

[19]Gupta, A. K. and Govindarajan, V. (2000). "Knowledge management's social dimension: lessons from Nucor Steel”, Sloan Management Review, Vol. 42, No. 1, pp. 7180.

[20]Yang, J-T. and Wan, C-S. (2003). "Advancing organizational effectiveness and knowledge management implementation", Tourism Management, Vol. 25, No. 5, pp. 593-601.

[21]Odabaş, H. (2006). Bilgi yönetimi. In Bilgi... (pp. 99-108). Referans Yayıncılik.

[22]Ekici, S. (2021). Ulusal Bilim ve Teknoloji Politikalarinda Bilgi Yönetimine Yaklaşim: Türkiye için Bir Strateji ve Eylem Planı Model Önerisi, Hacettepe Üniversitesi Sosyal Bilimler Enstitüsü Bilgi ve Belge Yönetimi Anabilim Dalı, Doktora Tezi, Ankara.

[23]Bayraktar, D. M. (2012). Teknolojik Yeniliğin Benimsenmesinde Sosyal Sistem Özelliklerinin Etkileri; EOkul Uygulamasının İncelenmesi. Hayef Journal Of Education, 9(1), 86-100.

[24]Lee, G., \& Xia, W. (2006). Organizational size and IT innovation adoption: A meta-analysis. Information \& Management, 43(8), 975-985.

[25]Yılmaz, M., \& Demirkan, A. E. (2012). Hastane yönetim ve bilgi sisteminin kullanılabilirliğinin değerlendirilmesi. Bilişim Teknolojileri Dergisi, 5(3), 19-28.

[26]UNESCO. (2010). Management Capacity, Guidebook for planning education in emergencies and reconstruction (pp. 153-154). Paris: Unesco.

[27]Moses, K. (2001). Education Management Information System: What is it and Why do we not have more of it?'. Journal of TechKnowLogia.

[28]Haddad, W. D. (2012). ICTs for Education A Reference Handbook, Part 1: Decision Makers Essentials.

[29]Hua, H., \& Herstein, J. (2003). Education Management Information System (EMIS): Integrated Data and Information Systems and Their Implications In Educational Management. Paper presented at the Annual Conference of Comparative and International Education Society, March 2003.

[30]Carrizo, L., Sauvageot, C., \& Bella, N. (2003). Information tools for the preparation and monitoring of education plans. Paris: Unesco. 